\title{
Natural Gas to Fuels and Chemicals: Improved Methane Aromatization in an Oxygen-Permeable Membrane Reactor**
}

\author{
Zhengwen Cao, Heqing Jiang, * Huixia Luo, Stefan Baumann, Wilhelm A. Meulenberg, \\ Jens Assmann, Leslaw Mleczko, Yi Liu, and Jürgen Caro*
}

Methane dehydroaromatization (MDA) is attracting considerable interest from both academia and industry because of its potential in the conversion of methane into chemicals and liquid fuels. ${ }^{[1]}$ Compared to the conventional liquid fuels production based on Fischer-Tropsch technology from syngas $\left(\mathrm{CO}+2 \mathrm{H}_{2}\right)$, MDA provides a simple, straightforward, and economic pathway from methane to aromatic hydrocarbons without intermediate steps. Intensive efforts have been devoted to the development of suitable catalysts, such as Zn/HZSM-5, ${ }^{[2]}$ Fe/HZSM-5, ${ }^{[3]}$ and Ga/HZSM-5, ${ }^{[4]}$ and encouraging progress has been made, especially on $\mathrm{Mo} /$ MCM-22, ${ }^{[5]}$ Mo/HMCM-49, ${ }^{[6]}$ and Mo/HZSM-5. ${ }^{[2,7]}$

Challenging problems still exist, such as the rapid catalyst deactivation by coke and the limited methane conversion, which hinder the industrialization of MDA. ${ }^{[8]}$

To overcome the equilibrium limitation of Reaction (1), it is proposed that the generated hydrogen can be removed by hydrogen-permeable membranes (metal alloys, zeolite or other molecular sieves, proton/electron conducting ceramics). ${ }^{[9]}$ Using a Pd-coated $\mathrm{Nb}-\mathrm{Ta}$ membrane, the methane conversion could be increased from $3.8 \%$ to $9 \%$ at $600{ }^{\circ} \mathrm{C}$; however, hydrogen removal resulted in accelerated coking. ${ }^{[\mathrm{b}]}$ Thermodynamically favorable is the substitution of the non-

[*] Z. Cao, Dr. H. Luo, Dr. Y. Liu, Prof. Dr. J. Caro

Institute of Physical Chemistry and Electrochemistry

Leibniz University of Hannover

Callinstrasse 3A, 30167 Hannover (Germany)

E-mail: caro@pci.uni-hannover.de

Prof. Dr. H. Jiang

Key Laboratory of Biobased Materials, Qingdao Institute of

Bioenergy and Bioprocess Technology

Chinese Academy of Sciences

No.189 Songling Road, 266101 Qingdao (China)

E-mail: jianghq@qibebt.ac.cn

Dr. H. Luo

Department of Chemistry, Princeton University

Princeton, N) 08544 (USA)

Dr. S. Baumann, Dr. W. A. Meulenberg

Forschungszentrum Jülich $\mathrm{GmbH}$

Institute of Energy and Climate Research

Leo-Brandt-Strasse, 52425 Jülich (Germany)

Dr. J. Assmann, Prof. Dr. L. Mleczko

Bayer Technology Services GmbH, BTS-TD-UP-Chemical Catalysis 51368 Leverkusen (Germany)

[**] Financial support from EU through FP7 NEXT-GTL project (grant agreement no. 229183) is kindly acknowledged. H.J. gratefully thanks the support via "Recruitment Program of Global Youth Experts" of China.

D)

Supporting information for this article is available on the WWWW under http://dx.doi.org/10.1002/anie.201307935. oxidative MDA according to Reaction (1) by the oxidative MDA according to Reaction (2).

$6 \mathrm{CH}_{4} \rightleftharpoons \mathrm{C}_{6} \mathrm{H}_{6}+9 \mathrm{H}_{2}$

$6 \mathrm{CH}_{4}+{ }^{9} / 2 \mathrm{O}_{2} \rightarrow \mathrm{C}_{6} \mathrm{H}_{6}+9 \mathrm{H}_{2} \mathrm{O}$

Additionally, the latter has been demonstrated to be efficient in suppressing the coke formation by the presence of oxygen and steam. ${ }^{[10]}$ However, the presence of stoichiometric oxygen concentrations inhibits the formation of molybdenum carbide, the active catalyst component essential for the formation of aromatic compounds. ${ }^{[7 a, 11]}$ As a result, side reactions such as the total and/or partial methane oxidation and the oxidative coupling of methane can become predominant, and the target product selectivity decreases. To manipulate the incompatible reactions mentioned above in the presence of oxygen, various oxygen introduction strategies have been proposed. For example, previous work suggested a mode in which minor amounts of oxygen or soft oxidants were co-fed together with methane..$^{[10,12]}$ Nevertheless, this concept suffers from a significant decrease of the aromatic productivity starting already for a low oxygen concentration in the fed methane, for example, less than $1 \%$ at $700{ }^{\circ} \mathrm{C}$. Furthermore, from safety aspect, the avoidance of hot spots or even explosions in such co-feeding mode should also be considered.

To obtain an improved MDA with increased methane conversion with an acceptable aromatic compound selectivity and better coking resistance, oxygen has to be finely distributed and continuously fed into the reactor, for example by using an oxygen-transporting membrane. ${ }^{[13]}$ Recently, we developed a series of membranes for versatile applications, for example, $\mathrm{CO}_{2}$ capture integrated in oxy-fuel power plants, ${ }^{[14]}$ direct decomposition of $\mathrm{NO}$ and $\mathrm{NO}_{2},{ }^{[15]}$ and the coupling of two reactions such as water splitting with the partial oxidation of methane/oxidative dehydrogenation of ethane. ${ }^{[16]}$

Herein we integrate the oxygen generation and MDA in a membrane reactor system, which is considered to offer a significant advantage for MDA. As illustrated in Figure 1, in the membrane reactor, oxygen permeates from the air side to the hydrocarbon side, where it is consumed in MDA. In contrast to the conventional co-feeding of gaseous $\mathrm{O}_{2}$ in the fixed-bed reactor, here oxygen is continuously fed into the reaction chamber by the oxygen-permeable membrane; a higher ratio of the oxidative MDA to side reactions can be expected without oxidative destruction of the active catalyst component $\mathrm{Mo}_{2} \mathrm{C}$. Furthermore, the presence of 
Fixed-bed reactor

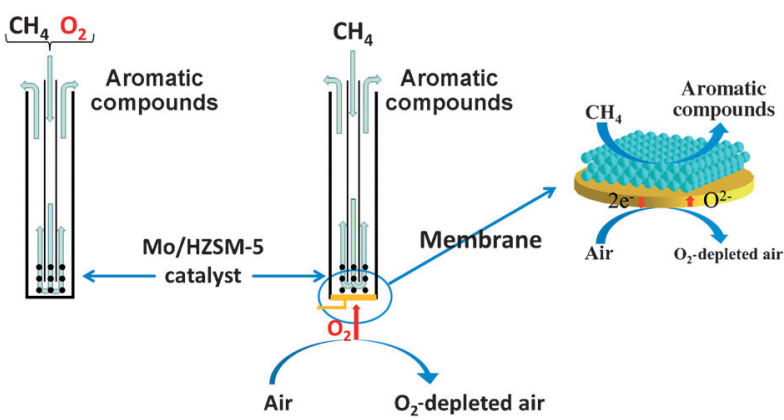

Figure 1. Methane dehydroaromatization (MDA) in a fixed-bed reactor $(\mathrm{FR})$ and membrane reactor (MR).

oxygen and the production of steam by hydrogen combustion should suppress the coke formation and extend the lifetime of the catalytic system. The membrane reactor used in this work is based on asymmetric oxygen transporting $\mathrm{Ba}_{0.5} \mathrm{Sr}_{0.5} \mathrm{Co}_{0.8} \mathrm{Fe}_{0.2} \mathrm{O}_{3-\delta}$ (BSCF) perovskite membrane consisting of $20 \mu \mathrm{m}$ thick BSCF dense layer on a porous BSCF support (Supporting Information, Figure S1). ${ }^{[17]}$ As the catalyst we used an established bifunctional Mo/HZSM-5 ( $\mathrm{Si} / \mathrm{Al}=$ 27, weight $\% \mathrm{Mo}=6$ ).

We performed the experiments in both a fixed-bed reactor (FR) and membrane reactor (MR) to observe the direct effect of oxygen supply via the membrane on MDA. First, both reactors were purged for $2 \mathrm{~h}$ with $\mathrm{He}$, and then methane was supplied. In the case of MR, $1 \mathrm{~h}$ after the methane supply the air supply started. That is to say, in the membrane reactor the MDA proceeded without oxygen permeation in the first hour, and then oxygen was supplied via the membrane. Figure 2 presents the methane conversion obtained in the MR and the $\mathrm{FR}$ as a function of time at $750^{\circ} \mathrm{C}$. The methane conversions in both reactors were comparable in the first hour. However, immediately after the oxygen permeation started in the MR, the conversion of methane increased and became higher than that in the FR with time on-stream. The main reason is that the MDA is thermodynamically more favorable in the

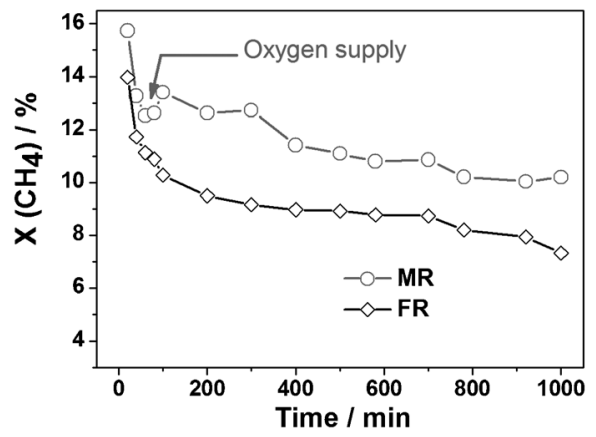

Figure 2. Methane conversions in a membrane reactor $(M R)$ and fixedbed reactor (FR) as a function of time. Mo/HZSM-5 (0.2 g, 6 wt \%) was used in both reactors (FR: $F_{\mathrm{CH}_{4}}=10 \mathrm{~cm}^{3} \mathrm{~min}^{-1}, F_{\mathrm{Ar}}=1 \mathrm{~cm}^{3} \mathrm{~min}^{-1}$, and $F_{\mathrm{He}}=9 \mathrm{~cm}^{3} \mathrm{~min}^{-1}$; MR: methane side, $F_{\mathrm{CH}_{4}}=10 \mathrm{~cm}^{3} \mathrm{~min}^{-1}$, $F_{\mathrm{Ar}}=1 \mathrm{~cm}^{3} \mathrm{~min}^{-1}$, and $F_{\mathrm{He}}=9 \mathrm{~cm}^{3} \mathrm{~min}^{-1}$; air side $F_{\mathrm{Air}}=30 \mathrm{~cm}^{3} \mathrm{~min}^{-1}$ ). Oxygen supply (air feed) began in the MR $1 \mathrm{~h}$ after starting the MDA reaction with dosing methane. presence of oxygen, thus the equilibrium of the reaction is shifted to the product side when the permeated oxygen in situ oxidizes the hydrogen liberated from the MDA reaction. Furthermore, the generation of steam reduces coking and extends the lifetime of the catalyst. As a result, the usual deactivation of the MDA catalytic process proceeds more slowly in the MR.

Figure 3 a shows that the selectivity of aromatic compounds drops sharply in both reactors with time on-stream. However, whereas the selectivity in the FR continuously dropped with time on-stream, in the case of MR it reached a plateau. Whereas the selectivity of aromatic compounds in the FR was only $10 \%$ after 1000 min time on-stream, the MR still shows a selectivity of about $30 \%$. Thermodynamically,
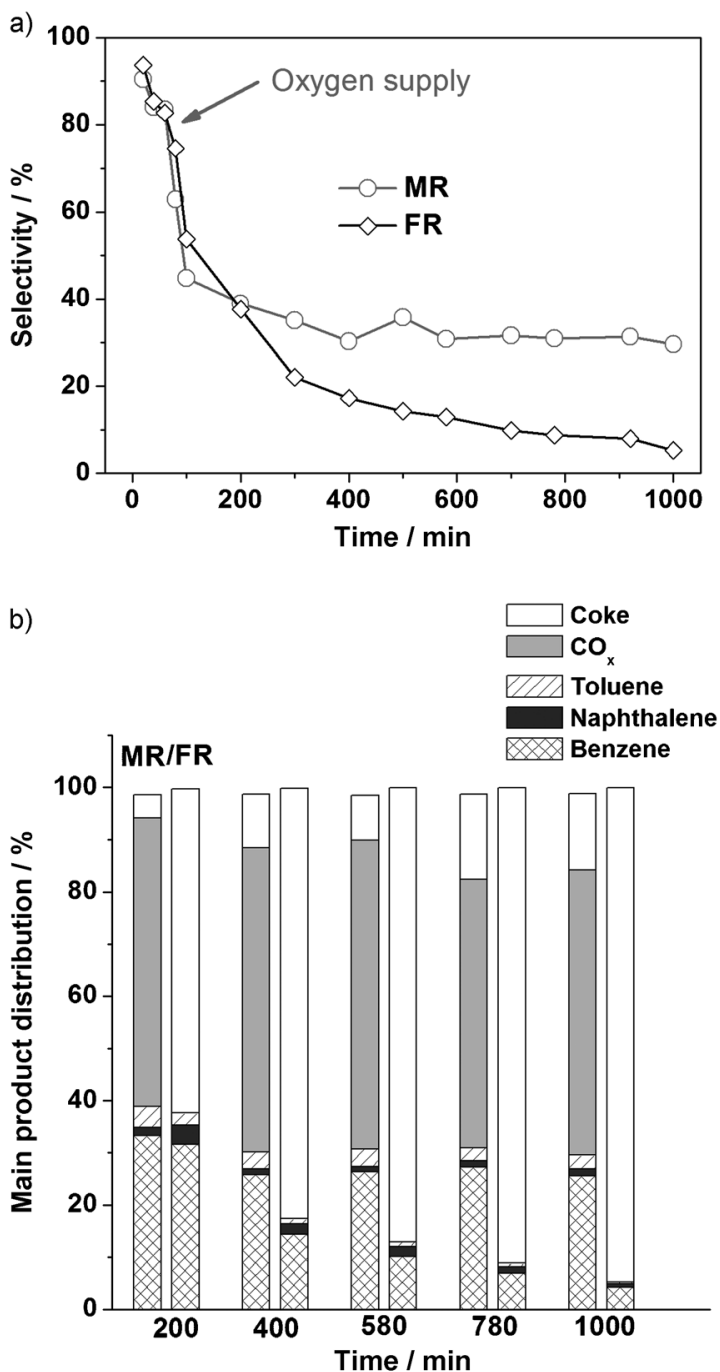

Figure 3. Selectivity of aromatic compounds (a) and the corresponding product distribution (b) based on carbon balance in the membrane reactor (MR) and fixed-bed reactor (FR) as a function of time. Mo/ HZSM-5 (0.2 g, 6 wt \%) was packed in both reactors (FR:

$F_{\mathrm{CH}_{4}}=10 \mathrm{~cm}^{3} \mathrm{~min}^{-1}, F_{\mathrm{Ar}}=1 \mathrm{~cm}^{3} \mathrm{~min}^{-1}$ and $F_{\mathrm{He}}=9 \mathrm{~cm}^{3} \mathrm{~min}^{-1} ; \mathrm{MR}$ : methane side, $F_{\mathrm{CH}_{4}}=10 \mathrm{~cm}^{3} \mathrm{~min}^{-1}, F_{\mathrm{Ar}}=1 \mathrm{~cm}^{3} \mathrm{~min}^{-1}$ and $F_{\mathrm{He}}=9 \mathrm{~cm}^{3} \mathrm{~min}^{-1}$; air side $F_{\text {Air }}=30 \mathrm{~cm}^{3} \mathrm{~min}^{-1}$ ). Oxygen supply (air feed) began in MR $1 \mathrm{~h}$ after starting the MDA reaction with dosing methane. $S\left(C_{2}\right)$ is around $1 \%$ and not presented here. 
the partial/total oxidation of methane under oxidative conditions is more favorable than the oxidative dehydroaromatization of methane. As a result, partial methane was oxidized to $\mathrm{CO}_{x}$ (see Figure $3 \mathrm{~b}$ ), which decreased the aromatic compound selectivity. Nevertheless, the MR still showed a superior selectivity over the FR, indicating that the presence of oxygen has not damaged the catalyst, especially the active compound $\mathrm{Mo}_{2} \mathrm{C}$. With increasing time on-stream, the selectivity in both reactors decreases, however, the MR shows a much higher resistance towards catalyst deactivation owing to the presence of oxygen and steam, as discussed below.

The higher methane conversion and higher selectivity aromatic compounds in the MR compared with the in the FR gives higher yield of aromatic compounds in the MR (Table 1). After $200 \mathrm{~min}$, the yield of aromatic compounds in MR is $30 \%$ higher than in the FR, after 500 min by $200 \%$.

Table 1: Yield of aromatic compounds (benzene, toluene, and naphthalene) in the membrane reactor (MR) and fixed-bed reactor (FR) as a function of reaction time. ${ }^{[a]}$

\begin{tabular}{lll}
\hline$T$ [min] & \multicolumn{2}{c}{ Yield of aromatic compounds [\%] } \\
& Membrane reactor & Fixed-bed reactor \\
\hline 100 & 6.0 & 5.5 \\
200 & 4.9 & 3.6 \\
500 & 4.0 & 1.3 \\
580 & 3.3 & 1.1 \\
1000 & 3.0 & 0.4 \\
\hline
\end{tabular}

[a] Mo/HZSM-5 (0.2 g $6 \mathrm{wt} \%)$ was packed in both reactors (FR: $F_{\mathrm{CH}_{4}}=10 \mathrm{~cm}^{3} \mathrm{~min}^{-1}, F_{\mathrm{Ar}}=1 \mathrm{~cm}^{3} \mathrm{~min}^{-1}$, and $F_{\mathrm{He}}=9 \mathrm{~cm}^{3} \mathrm{~min}^{-1} ; \mathrm{MR}$ : methane side, $F_{\mathrm{CH}_{4}}=10 \mathrm{~cm}^{3} \mathrm{~min}^{-1}, F_{\mathrm{Ar}}=1 \mathrm{~cm}^{3} \mathrm{~min}^{-1}$, and

$F_{\mathrm{He}}=9 \mathrm{~cm}^{3} \mathrm{~min}^{-1}$; air side $F_{\text {Air }}=30 \mathrm{~cm}^{3} \mathrm{~min}^{-1}$ ). Oxygen supply (air feed) began in MR $1 \mathrm{~h}$ after starting the MDA reaction with dosing methane.

In contrast to the poor yield of aromatic compounds $(<1 \%)$ of the FR after about $600 \mathrm{~min}$, the yield is still about $3 \%$ in the MR with increasing time on-steam. Based on this experimental finding, it can be concluded that the oxygen addition via the perovskite BSCF membrane is an effective way to enhance the performance of MDA.

To qualify the advantage of supplying oxygen via the membrane, we conducted also the oxidative MDA in the FR by co-feeding oxygen and methane. $0.4 \mathrm{~cm}^{3} \mathrm{~min}^{-1}$ gaseous $\mathrm{O}_{2}$ was fed into the fixed bed after the reactor had been conditioned for $1 \mathrm{~h}$ with methane to form the active catalyst phase $\mathrm{Mo}_{2} \mathrm{C}$. As shown in Figure 4, the selectivity of aromatic compounds decreases dramatically for the FR with gaseous oxygen from $85 \%$ to $5 \%$ after $100 \mathrm{~min}$, but for the MR only from $85 \%$ to $40 \%$. This finding can be explained by the oxidative destruction of the $\mathrm{Mo}_{2} \mathrm{C}$ catalyst in the oxygen cofeed FR. Normally, $\mathrm{Mo}_{2} \mathrm{C}$ catalysts tend to deactivate towards MDA when the $\mathrm{O}_{2} / \mathrm{CH}_{4}$ molar ratio concentration exceeds a critical value for a given temperature because of the oxidation of the active catalyst component $\mathrm{Mo}_{2} \mathrm{C}$ of the $\mathrm{Mo} /$ HZSM-5 catalyst, which interrupts the production of aromatic compounds immediately. According to Yuan et al., the critical value at $750{ }^{\circ} \mathrm{C}$ is around $0.02 .^{[10]}$ Therefore, the introduction of $0.4 \mathrm{~cm}^{3} \mathrm{~min}^{-1}$ gaseous $\mathrm{O}_{2}\left(\mathrm{O}_{2} / \mathrm{CH}_{4}\right.$ molar

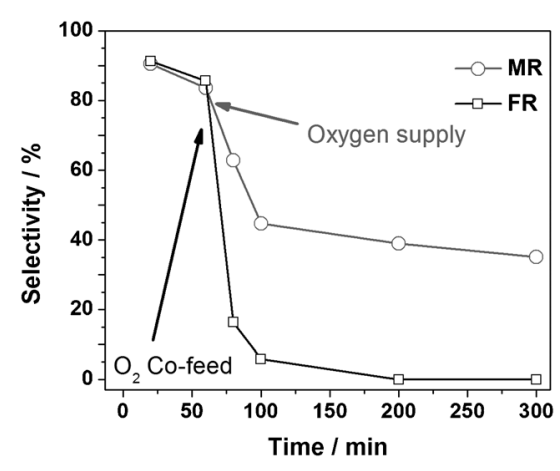

Figure 4. Selectivity of aromatic compounds as a function of time in the presence of oxygen in the two different reactors: A methane/ oxygen was fed into fixed bed reactor ( $\mathrm{FR}: F_{\mathrm{CH}_{4}}=10 \mathrm{~cm}^{3} \mathrm{~min}^{-1}$, $F_{\mathrm{O}_{2}}=0.4 \mathrm{~cm}^{3} \mathrm{~min}^{-1}, F_{\mathrm{Ar}}=1 \mathrm{~cm}^{3} \mathrm{~min}^{-1}$ and $\left.F_{\mathrm{He}}=8.6 \mathrm{~cm}^{3} \mathrm{~min}^{-1}\right)$. In the case of the membrane reactor (MR), oxygen was supplied from air through the BSCF membrane (MR, methane side, $F_{\mathrm{CH}_{4}}=10 \mathrm{~cm}^{3} \mathrm{~min}^{-1}$, $F_{\mathrm{Ar}}=1 \mathrm{~cm}^{3} \mathrm{~min}^{-1}$, and $F_{\mathrm{He}}=9 \mathrm{~cm}^{3} \mathrm{~min}^{-1}$; air side $\left.F_{\mathrm{Air}}=30 \mathrm{~cm}^{3} \mathrm{~min}^{-1}\right)$; Mo/HZSM-5 (0.2 g, 6 wt \%) was used in both reactors. Oxygen supply (air feed) or $\mathrm{O}_{2}$ feed began $1 \mathrm{~h}$ after starting the MDA reaction with dosing methane.

ratio $=0.04)$ results in a rapid deactivation of the catalyst and the formation of aromatic compounds stopped immediately in the FR (Figure 4). In the MR, the amount of oxygen calculated based on the $\mathrm{CO}$ and $\mathrm{CO}_{2}$ at outlet is higher than $0.4 \mathrm{~cm}^{3} \mathrm{~min}^{-1}$, indicating that the oxygen permeation flux is higher than $0.4 \mathrm{~cm}^{3} \mathrm{~min}^{-1}$ and the ratio of $\mathrm{O}_{2} / \mathrm{CH}_{4}$ is above 0.04 . Nevertheless, the aromatization reaction still proceeds and the yield of aromatic compounds in the MR is higher than that in the FR, suggesting this critical value was increased at least to 0.04 when the oxygen was supplied in the MR by the BSCF membrane instead of using gaseous oxygen as co-feed in the FR.

The coke selectivities in the MR and the FR (see Figure $3 \mathrm{~b}$ ) in both cases increase with time on-stream. However, as expected, the coke selectivity in the MR is much lower than that in the FR. The coke selectivity in the FR is mostly higher than $60 \%$ and increasing with time, but the coke selectivity in the MR was found to be only around $10 \%$ and showing an only slight increase with time. The CS-2000 automatic analyzer which allowing the rapid determination of the carbon content in catalysts was employed to determine the carbon deposition on the spent catalysts from both reactors. It was found that the carbon content in the spent catalyst from FR was around $12 \mathrm{wt} \%$ after $40 \mathrm{~h}$, and the catalyst from MR had only a carbon content of $1.2 \mathrm{wt} \%$. These results demonstrate that the coke formation was efficiently suppressed in the MR.

Despite an improved performance in our MR, a slow deactivation of the catalyst was still observed. To elucidate the reason for this deactivation, the spent catalyst $(40 \mathrm{~h})$ from the MR was characterized by SEM. As shown in the Supporting Information, Figure S2, fiber-like particles were dispersed on the spent catalyst surface. EDXS revealed that these fiber-like particles are mainly composed of carbon, indicating that the coke is probably still the reason for the catalyst deactivation in the MR. 
In summary, the work presented here demonstrates a new concept to transform natural gas into liquids via improved methane dehydroaromatization using an oxygen-permeable membrane. The addition of oxygen by the membrane improves the methane conversion and the selectivity of aromatic compounds, and results in a lower deactivation of the catalyst in the membrane reactor. Therefore, the methane aromatization in the membrane reactor with oxygen dosing gives a better yield of aromatic compounds (benzene, toluene, and naphthalene) and a longer durability than in the fixedbed reactor.

\section{Experimental Section}

The asymmetric BSCF membrane was prepared by tape casting followed by sintering. More details can be found in previous reports. ${ }^{[17 a, 18]}$ The effective membrane area was $0.28 \mathrm{~cm}^{2}$; more detail can be found in the Supporting Information.

Received: September 9, 2013

Published online: November 7, 2013

Keywords: aromatic compounds - dehydroaromatization . membrane reactors $\cdot$ methane oxygen-permeable membranes

[1] a) J. H. Lunsford, Catal. Today 2000, 63, 165-174; b) T. V. Choudhary, E. Aksoylu, D. W. Goodman, Catal. Rev. Sci. Eng. 2003, 45, 151-203; c) V. R. Choudhary, A. K. Kinage, T. V. Choudhary, Science 1997, 275, 1286-1288.

[2] L. Wang, L. Tao, M. Xie, G. Xu, J. Huang, Y. Xu, Catal. Lett. 1993, $21,35-41$

[3] B. M. Weckhuysen, D. Wang, M. P. Rosynek, J. H. Lunsford, J. Catal. 1998, 175, 347-351.

[4] a) D. Wang, J. H. Lunsford, M. P. Rosynek, J. Catal. 1997, 169 , 347-358; b) Y. J. Li, J. N. Armor, J. Catal. 1994, 145, 1-9; c) B. S. Kwak, W. M. H. Sachtler, W. O. Haag, J. Catal. 1994, 149, $465-473$.

[5] N. Chu, J. Wang, Y. Zhang, J. Yang, J. Lu, D. Yin, Chem. Mater. 2010, 22, 2757-2763.

[6] D. Y. Wang, Q. B. Kan, N. Xu, P. Wu, T. H. Wu, Catal. Today 2004, $93-95,75-80$.

[7] a) Y. Xu, X. Bao, L. Lin, J. Catal. 2003, 216, 386-395; b) F. Solymosi, J. Cserényi, A. Szöke, T. Bánsági, A. Oszkó, J. Catal. 1997, 165, 150-161; c) L. Su, L. Liu, J. Zhuang, H. Wang, Y. Li, W. Shen, Y. Xu, X. Bao, Catal. Lett. 2003, 91, 155-168; d) H. Jiang, L. Wang, W. Cui, Y. Xu, Catal. Lett. 1999, 57, 95-102; e) N. Chu, J. Yang, J. Wang, S. Yu, J. Lu, Y. Zhang, D. Yin, Catal. Commun. 2010, 11, 513 - 517; f) J. Yang, S. Yu, H. Hu, Y. Zhang, J. Lu, J. Wang, D. Yin, Chem. Eng. J. 2011, 166, 1083-1089.
[8] D. Ma, D. Wang, L. Su, Y. Shu, Y. Xu, X. Bao, J. Catal. 2002, 208, $260-269$.

[9] a) K. Skutil, M. Taniewski, Fuel Process. Technol. 2006, 87, 511 521; b) M. C. Iliuta, F. Larachi, B. P. A. Grandjean, I. Iliuta, A. Sayari, Ind. Eng. Chem. Res. 2002, 41, 2371-2378; c) L. Li, R. W. Borry, E. Iglesia, Chem. Eng. Sci. 2002, 57, 4595-4604.

[10] S. Yuan, J. Li, Z. Hao, Z. Feng, Q. Xin, P. Ying, C. Li, Catal. Lett. 1999, 63, $73-77$.

[11] H. Zheng, D. Ma, X. Bao, Z. H. Jian, H. K. Ja, Y. Wang, C. H. F. Peden, J. Am. Chem. Soc. 2008, 130, 3722-3723.

[12] P. L. Tan, K. W. Wong, C. T. Au, S. Y. Lai, Appl. Catal. A 2003, $253,305-316$.

[13] a) C. S. Chen, S. J. Feng, S. Ran, D. C. Zhu, W. Liu, H. J. M. Bouwmeester, Angew. Chem. 2003, 115, 5354-5356; Angew. Chem. Int. Ed. 2003, 42, 5196-5198; b) Y. Liu, X. Zhu, M. Li, H. Liu, Y. Cong, W. Yang, Angew. Chem. 2013, 125, 3314-3318; Angew. Chem. Int. Ed. 2013, 52, $3232-3236$; c) X. Dong, W. Jin, N. Xu, K. Li, Chem. Commun. 2011, 47, 10886-10902; d) P. Zeng, Z. Chen, W. Zhou, H. Gu, Z. Shao, S. Liu, J. Membr. Sci. 2007, 291, 148-156; e) J. Sunarso, S. Baumann, J. M. Serra, W. A. Meulenberg, S. Liu, Y. S. Lin, J. C. Diniz da Costa, J. Membr. Sci. 2008, 320, 13-41; f) U. Balachandran, T. H. Lee, S. E. Dorris, Int. J. Hydrogen Energy 2007, 32, 451-456; g) H. J. M. Bouwmeester, Catal. Today 2003, 82, 141-150; h) Z. Shao, W. Yang, Y. Cong, H. Dong, J. Tong, G. Xiong, J. Membr. Sci. 2000, 172, 177-188.

[14] a) H. X. Luo, K. Efimov, H. Q. Jiang, A. Feldhoff, H. H. Wang, J. Caro, Angew. Chem. 2011, 123, 785-789; Angew. Chem. Int. Ed. 2011, 50, 759-763; b) H. Luo, H. Jiang, T. Klande, Z. Cao, F. Liang, H. Wang, J. Caro, Chem. Mater. 2012, 24, $2148-2154$.

[15] a) H. Q. Jiang, H. H. Wang, F. Y. Liang, S. Werth, T. Schiestel, J. Caro, Angew. Chem. 2009, 121, 3027-3030; Angew. Chem. Int. $E d$. 2009, 48, 2983-2986; b) H. Q. Jiang, L. Xing, O. Czuprat, H. H. Wang, S. Schirrmeister, T. Schiestel, J. Caro, Chem. Commun. 2009, 6738-6740.

[16] a) H. Q. Jiang, H. H. Wang, S. Werth, T. Schiestel, J. Caro, Angew. Chem. 2008, 120, 9481-9484; Angew. Chem. Int. Ed. 2008, 47, 9341-9344; b) H. Q. Jiang, F. Y. Liang, O. Czuprat, K. Efimov, A. Feldhoff, S. Schirrmeister, T. Schiestel, H. H. Wang, J. Caro, Chem. Eur. J. 2010, 16, 7898-7903; c) H. Q. Jiang, Z. W. Cao, S. Schirrmeister, T. Schiestel, J. Caro, Angew. Chem. 2010, 122, 5790-5794; Angew. Chem. Int. Ed. 2010, 49, 5656-5660; d) A. M. Champagnie, T. T. Tsotsis, R. G. Minet, E. Wagner, $J$. Catal. 1992, 134, 713-730.

[17] a) S. Baumann, J. M. Serra, M. P. Lobera, S. Escolástico, F. Schulze-Küppers, W. A. Meulenberg, J. Membr. Sci. 2011, 377, 198-205; b) Z. Cao, H. Jiang, H. Luo, S. Baumann, W. A. Meulenberg, H. Voss, J. Caro, Catal. Today 2012, 193, $2-7$.

[18] F. Schulze-Küppers, S. Baumann, W. A. Meulenberg, D. Stöver, H. P. Buchkremer, J. Membr. Sci. 2013, 433, 121-125. 